\title{
LEAN TEAMS AND BEHAVIORAL DYNAMICS: UNDERSTANDING THE LINK
}

\author{
Elnaz Asadian ${ }^{1}$ and Robert M. Leicht ${ }^{2}$
}

\begin{abstract}
The emphasis of lean thinking on eliminating waste and improving production makes it easy to relate to the construction domain to have more successful projects. Several tools and techniques have been introduced to simplify lean adoption. However, the human side of lean has not yet seen the emphasis it deserves. Interdisciplinary teams are the implementers of lean practices within projects. Therefore, this study seeks to shed light on the nature of lean teams within construction projects. The human dynamics are mapped to the lean principles to investigate the link between these constructs and lean initiatives implementation. To support the alignment of team enablers with lean principles, eight constructs from the A_B_C framework of team psychology have been identified through the literature search, including openness, trust and psychological safety, cohesion, team viability, collaboration and communication, conflict, information sharing, and knowledge exchange. The findings highlight that organizations should consider the behavioral side of lean in a team context if they want to realize the full benefits of lean transformation. By emphasizing the importance of lean foundations within the organizational culture and team member behavior, construction teams will be able to develop the link necessary between team members' interactions and lean principles adoption.
\end{abstract}

\section{KEYWORDS}

Team dynamics, lean construction, collaboration, trust, culture.

\section{INTRODUCTION}

Lean philosophy, which emerged in automotive manufacturing, is a production method to achieve better outcomes, such as improved efficiency. The paradigm of continuous improvement gained popularity in other industries, namely construction, as a way to develop more productive environments. The term lean construction (LC), an overarching concept, encompasses the design and construction phases of a project, is defined as " $a$ way to design production systems to minimize waste of materials, time, and effort with an aim to generate the maximum possible amount of value" (Koskela et al. 2002 p. 211).

Since the introduction of lean principles, several studies have discussed the concept's fundamentals. Despite the ample literature on the theory behind the lean philosophy, we have witnessed many failed efforts. According to Aslam et al. (2020), the construction industry is struggling to adopt the full benefits of lean either due to the lack of awareness or complex strategies. Moreover, most of the prior research studies have generally

$1 \quad$ PhD Candidate, Architectural Engineering Department, Pennsylvania State University, University Park, PA 16801, USA, eza234@psu.edu, orcid.org/0000-0002-3146-7725

2 Associate Prof., Architectural Engineering Department, Pennsylvania State University, University Park, PA 16801, USA, rml167@psu.edu, https://orcid.org/0000-0001-6705-8141 
targeted lean instruments and application of new technologies. Low emphasis has been assigned to project participants, leaving aside organizational and human issues (Pavez and Alarcón 2006). Simply implementing the best lean methods does not guarantee success. Understanding the culture of lean is needed to assist organizations in successfully adopting and sustaining lean strategies. In this respect, some research studies have tried to identify behavioral dynamics that constitute a thriving lean culture (Van Dun and Wilderom 2012). Most of them focus on manufacturing and other businesses, rather than construction. Therefore, there is a dearth of studies within the construction domain.

This paper aims to identify how lean principles align with the design of teams in a construction context. To determine the links between lean theory and teams, this research will explore literature on team attributes, behavioral dynamics, and sociocultural indicators that underpin lean teams' performance. Ultimately, we seek to understand how team dynamics influence the way lean teams operate.

A subset of lean principles is briefly introduced in this paper, followed by describing the "lean team" concept in construction. Lastly, by linking the human dynamics with lean principles, a comparison of lean principles and ideas with the internal dynamics of effective lean teams was investigated to understand how construction team efforts could be supported more effectively. The study's findings will serve as the initial development of a framework to capture the human side of lean implementation, which must be considered by construction companies if they want to realize the full benefits of lean transformation. By emphasizing the importance of lean foundations within the organizational culture and team member behavior, construction teams will be able to create the necessary human conditions for adopting and sustaining lean principles.

\section{LITERATURE REVIEW}

\section{LEAN PRINCIPLES AND IDEAS}

In 1992, Koskela proposed eleven principles for flow process design and improvement. These principles are: reduce the share of non-value-adding activities, increase output value through systematic consideration of customer requirements, reduce variability, reduce the cycle time, simplify by minimizing the number of steps and parts, increase output flexibility, increase process transparency, focus control on the complete process, build continuous improvement into the process, balance flow improvement with conversion improvement, and benchmark. He highlighted that approaches to the new production philosophy have originated around one central principle, even if they usually acknowledge other principles. Therefore, many principles are closely related but not on the same abstraction level. Some are more fundamental, while others are more application-oriented (Koskela 1992). Subsequently, Koskela and Leikas (1997) added "focus on the whole processes and optimize the whole" as an overarching lean principle.

Womack and Jones (1997) established five principles of lean: value, value stream, flow, pull, and perfection. In the same year, Melles, in his book, What do we mean by lean production in construction, listed seven basic principles of lean production, including multifunctional task groups, simultaneous engineering, kaizen, just-in-time deliveries, co-makership, customer orientation, and information, communication and process structure (Melles 1997). In 2005, Pinch pointed out the following principles as LC principles: establishing integrated teams and collaboration, combining project design with process design, stopping production rather than releasing a faulty product into construction, decentralizing decision-making and empowering project participants, 
making the process transparent, and requiring a simple, direct handoff between tasks (Pinch 2005). These are only some of the previous studies discussing lean principles. Although each scholar presented different terms, similarities are apparent in the principles. Some principles, such as continuous improvement, perfection, customer orientation, decentralizing decision-making, and optimizing the whole, will be discussed in this paper to investigate the relationship between team dynamics and lean principles.

\section{CONSTRUCtion Teams and TEAM-OrIENTEd APPROACH}

Teams are the appropriate unit for high complexity tasks with many interdependent subtasks, like construction activities. Katzenbach and Smith (2015) defined a "True Team" as a small group of people with complementary skills committed to a common purpose. They also commit to an approach for which they hold themselves mutually accountable.

The team concept was first employed as a management practice for organizations that wanted to become more flexible and harness employees' creative capacities. This practice showed numerous benefits, including higher productivity, improved quality, and increased employee morale (Johnson et al. 2000). In the context of work team applications, four broad categories were proposed: advice and involvement, production and service, projects and development, and action and negotiation. Under the production team category, teams use technology to generate products or services, such as teams in construction. (Sundstrom et al. 1990). Considering construction as team-based production can explain the linkage between team dynamics with production theory, namely lean.

Several scholars have highlighted the vital role of teamwork in construction activities. Spatz (2000) claimed that "if any industry should appreciate the importance of teamwork, that is the construction industry." Based on his study, teamwork can be traced back to construction projects' foundation and cultural heritage. In addition, the complex social and technical aspects of construction projects require teamwork to allow specialized individuals to work collaboratively at the job sites or during the project's design phases.

Teamwork initiatives in construction projects generally focus on improving how people interact. This is in accordance with what Liker (2004) emphasized as the two pillars that support lean implementation: "Continuous Improvement" and "Respect for People." Likewise, Shah and Ward (2007) defined lean production as an integrated sociotechnical system that eliminates waste by minimizing supplier, customer, and internal variability. Therefore, the attention to the social aspect of lean production, in parallel with the technical processes, necessitates the study of LC's human dimension.

\section{Crucial Role of Lean Teams in Construction}

Although lean thinking in both construction and manufacturing applies the same principles, there are some differences. One of the distinctions is the complicated interface among multiple entities in construction projects (Fahmy 2020). In construction, these parties have distinct organizational motivations and goals. However, in manufacturing, uncertainties can be almost eliminated by clearly defining the end product. Therefore, while lean manufacturing targets processes to achieve product goals, the lean approach in construction should address peoples' and entities' alignment with the overall project goals.

Van Amelsvoort and Benders (1996) also emphasized the role of lean teams when they called the team a hallmark of lean production, stating "teams emerge as the heart of the lean factory." Moreover, companies have realized that their major problems hindering the successful implementation of lean practices are driven by human, cultural, and organizational issues (Pavez and Alarcón 2006). The development of the team aspect of 
the lean approach is more complicated than merely adopting lean tools. Establishing and maintaining a productive team dynamic is one of the biggest challenges.

Team dynamics describe how unconscious psychological forces affect the behavior of groups of people working together (Wakeman and Langham 2018). Put simply, team dynamics define how team members interact (Gomez et al. 2020). According to Van Dun and Wilderom (2012), these dynamics include interaction behavior between team members and the leader, which were considered invisible to those working outside the team. They defined these internal interactions as the mediating or moderating factors that transform external inputs into collective team outcomes. Considering that the cornerstone of the lean approach in construction is the operations of the construction team, understanding and identifying the dynamics within the project team that helps align team outputs with project goals will ultimately increase the likelihood of project success.

\section{RESEARCH METHODOLOGY}

This paper explores theoretical foundations to establish the link between lean and teamwork in the construction domain. To do so, a systematic literature search using Google Scholar and ScienceDirect was conducted. Different combinations of general terms of lean, teams, culture, behavior, combined with dynamics, human side, and organization, were explored within the two search engines. All publications with the search terms in the title or keywords were extracted in the initial step, resulting in 74 articles. The 29 articles that concentrate on the construction industry's organizational settings were then selected for an in-depth study. Following this filtering, the selected papers' abstracts were then used to further narrow down the sample to the studies focused on lean teams in construction. In the final step, nine papers served as the analysis for the purpose of this study. A brief description of these papers is summarized in Table 1.

Table 1: Title, authors, and venue of papers analyzed in the research study

\begin{tabular}{|c|c|c|}
\hline Title & Authors & Publication \\
\hline $\begin{array}{l}\text { Lean, psychological safety, and behavior-based } \\
\text { quality: a focus on people and value delivery }\end{array}$ & (Gomez et al. 2020) & IGLC \\
\hline $\begin{array}{l}\text { Lean Principles Implementation in Construction } \\
\text { Management: A One Team Approach }\end{array}$ & (Fahmy 2020) & CIC 2020 \\
\hline $\begin{array}{l}\text { Towards a lean behavior evaluation system in Latin } \\
\text { American construction }\end{array}$ & $\begin{array}{l}\text { (Salvatierra et al. } \\
\text { 2020) }\end{array}$ & IGLC \\
\hline Building a lean culture into an organization & (Kalyan et al. 2018) & IGLC \\
\hline Building a Lean culture & (Hackler et al. 2017) & IGLC \\
\hline $\begin{array}{l}\text { Behavioral factors influencing lean information flow in } \\
\text { complex projects }\end{array}$ & (Phelps 2012) & IGLC \\
\hline $\begin{array}{l}\text { Understanding lean implementation: perspectives and } \\
\text { approaches of an American construction organization. }\end{array}$ & $\begin{array}{l}\text { (Chesworth et al. } \\
\text { 2011) }\end{array}$ & $\begin{array}{l}\text { ARCOM } \\
\text { Conference }\end{array}$ \\
\hline $\begin{array}{l}\text { An empirical study of information flows in } \\
\text { multidisciplinary civil engineering design teams using } \\
\text { lean measures }\end{array}$ & $\begin{array}{l}\text { (Tribelsky and } \\
\text { Sacks 2011) }\end{array}$ & $\begin{array}{l}\text { Archit. Eng. } \\
\text { Des. } \\
\text { Manage. }\end{array}$ \\
\hline $\begin{array}{l}\text { Qualifying people to support lean construction in } \\
\text { contractor organizations }\end{array}$ & $\begin{array}{l}\text { (Pavez and Alarcón } \\
\text { 2006) }\end{array}$ & IGLC \\
\hline
\end{tabular}




\section{A-B-C FRAMEWORK}

Salas et al. (2008) developed the A-B-C framework to establish a practical and concise means to understand teamwork. They proposed the framework to depict three essential aspects: Attitudes, shared Behaviors, and Cognition of the individuals that make up the team. These aspects define the local dynamics, which exist within a team's context.

Team dynamics contribute to the engagement processes of team performance. What team members do can be described by shared behaviors. What team members believe or feel can be portrayed by attitudes, while cognitions consist of what team members think or know. In this respect, the following constructs can be recognized (Delice et al. 2019):

- Attitudes: openness, trust, cohesion, team viability,

- Behaviors: collaboration, communication, conflict, leadership, and

- Cognitions: information and knowledge sharing, shared mental model.

In this paper, the A-B-C framework is employed due to its ability to capture the elements that shape effective team dynamics. It should be noted that more team constructs exist that can be investigated; however, due to space limitation, the authors concentrate on eight identified dynamics, specifically: openness, trust, cohesion, team viability, collaboration, communication, conflict, information and knowledge sharing. While leadership is one of the most important constructs, we do not have sufficient space for it to be fully considered. Similarly, shared mental models are an extensive topic and are not discussed in this paper. In the following section, the eight constructs will be discussed. These constructs are expanded upon and linked to construction literature, developing an initial understanding of the alignment of team dynamics with lean production principles.

\section{FINDINGS AND DISCUSSION}

This section investigates the association between team constructs and lean principles. The authors aim to introduce the relationships and discuss how lean teams are linked to the eight constructs from the A-B-C framework to investigate how lean principles support lean team constructs. Each construct is first introduced, then a comparison of lean principles and ideas with this team dynamic is presented.

\section{LEAN TEAM DYNAMICS}

\section{Openness}

The value of organizing work into teams is that each member does not need to be capable of doing everything on their own. Instead, they can have access to a broader pool of skills and ideas. In this context, the way people accept new ideas, actions, and values or react to them matters. Openness is defined as the degree to which teammates openly share and receive information. This construct can be used to recognize whether individuals will be able to trust one another and communicate differing opinions in the context of their team throughout the developmental stages of a team (Delice et al. 2019).

With "respect for people" as one of the main pillars of lean philosophy, team members are encouraged to be less dogmatic and rigid in their ideas. Instead, they are encouraged to consider different opinions in new situations. In the pursuit of continuous improvement, new concepts are frequently considered for activity improvement. Hence, it is necessary for lean teams to be open to the potential value of new practices. In construction projects, stakeholders come together from various organizations. Therefore, they should be open to ideas from project participants from other organizations to fully realize project benefits. 
This notion conforms with another lean principle, "optimize the whole," highlighting that companies should consider the entire supply chain process to satisfy their end customers' needs rather than concentrate only on their own work processes.

Moreover, as Van Dun and Wilderom (2012) described, lack of team openness can impair team members' communication and information sharing. Accordingly, a lower level of openness hinders the team's ability to generate innovative solutions, which is one of lean team pursuits under continuous improvement. Therefore, under the principles of respect for people, continuous improvement, and optimize the whole, a lean team is expected to possess sufficient openness to embrace different perspectives. Thus, openness acts as an underpinning dynamic for teams to effectively use lean principles in projects.

\section{Trust and Psychological Safety}

To date, no definition of trust has been universally accepted. However, "positive expectations towards the behavior of others" and "the willingness to become vulnerable to others" are consistently recognized as critical elements of trust. Trust is considered a psychological state influenced by the complex interrelations between expectations, intentions, and dispositions (Costa et al. 2018). Trust is often initially affected by an individual's openness to other team members to reduces ambiguity. In this environment, team members are open to taking risks and enhancing collaboration and cooperation. Moreover, trust can contribute to a psychologically safer environment, where team members feel comfortable discussing their opinions and viewpoints freely.

Trust between team members plays a pivotal role in the formation of lean teams and can be recognized as an enabler that supports the employee's contribution towards improving work practices. For example, Van Dun and Wilderom (2012), in their paper about lean teams in the manufacturing industry, reflected on two findings:

- With higher mutual trust, team members are more accepting of mutual monitoring.

- Mutual trust supports information sharing among team members.

Thus, they concluded that high team performance within teams requires members feeling psychologically safe to discuss errors or suggest improvements. Simultaneously, when team members feel responsible for maintaining and co-creating a high level of psychological safety, this may lead to increased team performance.

In one of the most comprehensive studies on psychological safety in the lean construction realm, Gomez et al. (2020) highlighted theoretical concepts to describe how lean principles and psychological safety are connected in a people-centered approach to improve value delivery. Based on this study, awareness of people's level of psychological safety can nurture lean principles, such as respect for people. As a result, under the culture of trust and within a psychologically safe environment, lean practices can be implemented more effectively to support project outcomes. A well-coordinated Last Planner meeting can be an excellent example of this type of trust.

Due to the high dependency of construction projects on teams, emphasis on trust and psychological safety support communication and idea-sharing to overcome project challenges. As a result, people's mindsets can be shifted towards pursuing learning and improvement. Quality expectations will be more likely to be met, and safety will become a priority for all (Gomez et al. 2020). Thus, a higher level of trust and psychological safety is supportive of lean teams' efforts to optimize the whole project. 


\section{Cohesion}

In its classic definition, cohesion refers to a field of forces making team members stay together. Since this early definition, a multidimensional view of cohesion has emerged to describe how various factors may affect team members to work together and remain united. For instance, a categorization of cohesion, including social cohesion, task cohesion, and group pride, was proposed. While social cohesion refers to a shared appeal to the team, i.e., interpersonal attraction and emotional friendship, task cohesion relates to a team's shared commitment to the team tasks to coordinate their efforts to achieve common work-related goals (Chiocchio and Essiembre 2009).

One of the lean principles is the consideration of customer requirements. Considering that team members serve as internal customers within the process, each member tries to coordinate their efforts to answer the work-related requests of their teammates. Previous studies confirmed this notion, suggesting that in the lean context, developing a cohesion level over a certain threshold is needed to become a lean team, and the team cohesiveness may grow over time. During the initial steps of adopting lean philosophy, teams may struggle to change things in their non-value-adding tasks, resulting in a lower team cohesiveness. However, at the more advanced stages of lean implementation, the team's cohesiveness level would be increased (Van Dun and Wilderom 2012). Thus, with respect to customer orientation, cohesion can be considered a key construct in lean teams.

\section{Team Viability}

Bell and Marentette (2011) defined team viability as a team's capacity for growth, which is required for success in future performance. It is sometimes viewed as a team members' willingness to remain in the team. Teams with higher social integration and cohesion experience higher member satisfaction, perform better at coordinating tasks and show higher team viability. However, team viability is understudied despite the importance of this construct for examining team maturity (Delice et al. 2019). Little has been done to develop the construct since the inclusion of team viability in team effectiveness models.

None of the previous studies on lean teams have explicitly emphasized this attribute. However, in terms of the links to lean principles and ideas, team viability is in close conformity with the principles of seeking perfection and continuous improvement. Additionally, in lean philosophy, a long-term vision has been emphasized as a lean management component. It is in line with organizational research that the social processes used should sustain team members' ability to work together on subsequent tasks (Bell and Marentette 2011). Yet, the temporary nature of construction project teams may inherently complicate the drive toward viability. Thus, the concept of team viability needs greater attention if the construction organization seeks lean principles. This could be achieved through building relationships across projects and the supply chain.

\section{Collaboration and Communication}

Collaboration is referred to the joint effort of two or more agents trying to achieve a common goal where members construct judgments and act based on them. Collaboration occurs when a group of autonomous stakeholders engages in an interactive process by using shared rules, norms, and structures to decide on issues related to a problem domain (Wood and Gray 1991). When team members collaborate, they bring different perspectives to handle complex problems, the resulting information processing capacity is increased. In this context, communication, the act of transferring information from one place to another, is key to effective collaboration and team functioning. 
Collaboration and communication play pivotal roles in completing a construction project. Melles (1997) highlighted information, communication and process structure as lean principles. In addition, Pinch (2005) pointed out establishing integrated teams and collaboration, and decentralizing decision-making and empowering project participants as lean principles. Similarly, according to Fahmy (2020), lean can be considered as a set of processes that allow project teams to collaborate efficiently to eliminate waste and maximize value. Hence, principles such as pull have been introduced to address collaboration across fragmented organizational boundaries of project teams. With these lean principles, it can be concluded that the stakeholders' collaboration and communication are a prerequisite of lean teams.

\section{Conflict}

Conflict is inherent in any team that even the most homogeneous groups cannot avoid. Conflict is recognized as a multidimensional construct involving tasks or relationships. In this respect, relationship conflict represents the individual's perception of the incompatibility of their teams. In contrast, task conflict is a disagreement among team members about their collective task decisions and ideas. However, with moderate levels, task conflict can be used constructively to enhance team performance (Delice et al. 2019).

The impact of conflict management on lean teams has been identified in previous studies. For instance, Van Dun and Wilderom (2012) showed that if a lean team is wellstructured, members are more likely to learn from work experiences, including conflict. Effective conflict resolution within teams is employed to secure issues, with lean teams extending this into learning and continuous improvement. Though conflict may arise, members will be open to each other's ideas within a healthy and safe team environment. Teams that effectively manage differences in personality and style have been more flexible by considering the team's good instead of focusing on their own achievement. This is in close correlation with the lean principle of optimizing the whole. When team members concentrate on the ultimate goal of having a better project, individual viewpoints will enable constructive conflict to benefit the overall project.

\section{Information Sharing and Knowledge Exchange}

Teams with systems for information sharing and knowledge exchange have been shown to manage conflicts more effectively and experience better performance outcomes. Information sharing is exchanging ideas amongst members, and knowledge exchange can be defined as sharing task-relevant ideas and information among members (Delice et al. 2019). These constructs hold great importance in the progression of team performance.

Van Dun and Wilderom (2012) showed that well-structured lean groups tend to share more information, affecting a team's learning orientation. This team construct is closely associated with "increase process transparency," where the process is made observable through the public display of information. Based on this lean principle, proper information sharing can make the production process transparent and visual, facilitating control, identifying waste, and enabling improvement. Hence, the increased process transparency supports the information sharing construct within lean teams.

\section{CONCLUSIONS}

Developing and sustaining effective lean teams is more challenging than merely adopting lean tools. Therefore, identifying what dynamics influence how lean teams operate can 
help align team constructs with lean principles. This paper applied the A-B-C framework to extract team constructs and map them to lean principles to find the links between them.

The findings revealed that team constructs, including openness, trust and psychological safety, cohesion, team viability, collaboration and communication, conflict, information sharing, and knowledge exchange, are closely aligned with the implementation of lean principles, namely respect for people, continuous improvement, perfection, optimizing the whole, customer orientation, increase process transparency, pull, and decentralizing decision-making. The study also revealed that although some of these team constructs have been emphasized in lean construction literature, some of them, namely team viability, have been neglected in previous studies. This suggests the need for a holistic framework of teams and lean principles to fill the gap of overlooking these fundamental team constructs. The findings of this study can help construction organizations to understand team dynamics to provide related training and coaching efforts. Further, as construction projects are often limited in their time and resources, the alignment of lean principles to improve production with improving the effectiveness of teams may help align and reinforce the implementation of both.

Although remarkable signs of progress have been made in adopting lean principles in construction, there is still much to learn about aligning the adoption of principles in the implementation of construction teams. To continue the study and refine links introduced here, we intend to study lean teams' formation and development during the life of projects.

\section{REFERENCES}

Aslam, M., Gao, Z., and Smith, G. (2020). "Exploring factors for implementing lean construction for rapid initial successes in construction.” J. Cleaner Prod., 277, 123295.

Bell, S. T., and Marentette, B. J. (2011). "Team viability for long-term and ongoing organizational teams." Organ. Psychol. Rev., 1(4), 275-292.

Chesworth, B., London, K., and Gajendran, T. (2011). "Understanding lean implementation: perspectives and approaches of an American construction organization." 27th Annual ARCOM Conference, 321.

Chiocchio, F., and Essiembre, H. (2009). "Cohesion and Performance: A Meta-Analytic Review of Disparities Between Project Teams, Production Teams, and Service Teams." Small Group Research, 40(4), 382-420.

Costa, A. C., Fulmer, C. A., and Anderson, N. R. (2018). "Trust in work teams: An integrative review, multilevel model, and future directions." J. Organ. Behav., 39(2), 169-184.

Delice, F., Rousseau, M., and Feitosa, J. (2019). "Advancing Teams Research: What, When, and How to Measure Team Dynamics Over Time." Front. Psychol., 10, 1324.

Fahmy, M. (2020). "Lean Principles Implementation in Construction Management: A One Team Approach." Qatar University Press.

Gomez, S., Ballard, G., Arroyo, P., Hackler, C., Spencley, R., and Tommelein, I. D. (2020). "Lean, Psychological Safety, and Behavior-Based Quality: A Focus on People and Value Delivery." Proc. 28thAnnual Conference of the International Group for Lean Construction (IGLC28), Berkeley, California, USA, 97-108.

Hackler, C., Byse, E., Reed, D., and Alves, T. (2017). "Building a Lean culture." Proceedings for the 25th Annual Conference of the International Group for Lean Construction (IGLC25), 309-316.

Katzenbach, J. R., and Smith, D. K. (2015). "The Wisdom of Teams: Creating the HighPerformance Organization." Harvard Business Review Press. 
Kalyan, V., Pratap, V., and Singh, S. C. (2018). "Building a lean culture into an organization." 26th Annual Conference of the International Group for Lean Construction (IGLC26).

Koskela, L. (1992). "Application of the new production philosophy to construction." Citeseer, Stanford: Stanford University.

Koskela, L., and Leikas, J. (1997). "Lean manufacturing of construction components." Lean construction. Alarcón, L.(ed.). AA Balkema, Rotterdam, 263-271.

Koskela, L., Howell, G., Ballard, G., and Tommelein, I. (2002). "The foundations of lean construction." Design and Construction: Building in value, 291, 211-226.

Johnson, P. R., Heimann, V. L., and O'Neill, K. (2000). “The wolf pack: team dynamics for the 21 st century." Journal of Workplace Learning, MCB UP Ltd, 12(4), 159-164.

Liker, J. K. (2004). "The Toyota Way: 14 management principles from the world's greatest manufacturer." McGraw-Hill, New York, 109-111.

Melles, B. (1997). "What do we mean by lean production in construction." Lean Construction, AA Balkema Rotterdam, 1, 11-16.

Pavez, I., and Alarcón, L. F. (2006). "Qualifying people to support lean construction in contractor organizations." Proc. 14th Annual Conference of the International Group for Lean Construction, 513-524.

Phelps, A. F. (2012). "Behavioral factors influencing lean information flow in complex projects." Proceedings of the 20th annual conference of the international group for Lean Construction, Citeseer.

Pinch, L. (2005). "Lean construction." Construction Executive, 15(11), 8-11.

Salas, E., Cooke, N. J., and Rosen, M. A. (2008). "On Teams, Teamwork, and Team Performance: Discoveries and Developments." Human Factors, 50(3), 540-547.

Salvatierra, J. L., García, A., and Aracena, P. (2020). "Towards a lean behaviour evaluation system in Latin American construction." IGLC, Berkeley, California, USA.

Shah, R., and Ward, P. T. (2007). "Defining and developing measures of lean production." J. Oper. Manage., 25(4), 785-805.

Spatz, D. M. (2000). "Team-Building in Construction." Pract. Period. Struct. Des. Constr., 5(3), 93-105.

Sundstrom, E., De Meuse, K. P., and Futrell, D. (1990). "Work teams: Applications and effectiveness." American psychologist, 45(2), 120.

Tribelsky, E., and Sacks, R. (2011). "An empirical study of information flows in multidisciplinary civil engineering design teams using lean measures." Archit. Eng. Des. Manage., Taylor \& Francis, 7(2), 85-101.

Van Amelsvoort, P., and Benders, J. (1996). "Team time: a model for developing selfdirected work teams.” Int. J. Oper. Prod. Manag, 16(2), 159-170.

Van Dun, D. H., and Wilderom, C. P. M. (2012). "Human dynamics and enablers of effective lean team cultures and climates." International review of industrial and organizational psychology, 27, 115-152.

Wakeman, D., and Langham, M. R. (2018). "Creating a safer operating room: Groups, team dynamics and crew resource management principles." Seminars in Pediatric Surgery, 27(2), 107-113.

Womack, J. P., and Jones, D. T. (1997). "Lean thinking - banish waste and create wealth in your corporation." J. Oper. Res. Soc., Taylor \& Francis, 48(11), 1148-1148.

Wood, D. J., and Gray, B. (1991). "Toward a comprehensive theory of collaboration." The Journal of applied behavioral science, 27(2), 139-162. 